\title{
Does observed vs expected lung head ratio correlate with neonatal survival in infants with congenital diaphragmatic hernias?
}

\author{
Christine U Okpala, MD, ${ }^{1}$ Jason Picconi, MD, $\mathrm{PhD},{ }^{1}$ Jonathan M. Klein, MD, ${ }^{2}$ Frank $\mathrm{H}$. \\ Morriss, Jr., MD, MPH, ${ }^{2}$ Asha Rijhsinghani, MD, ${ }^{1}$ Nina Nuangchamnong, $\mathrm{MD}^{1}$
}

Keywords: Congenital diaphragmatic hernia, lung head ratio, oxygenation index

\section{Objective}

To investigate whether observed vs expected (O/E) lung-to-head ratio (LHR) correlates with neonatal survival in infants with congenital diaphragmatic hernia $(\mathrm{CDH})$. Secondary goal was to correlate O/E LHR with Oxygenation index (OI) in the first 12 hours of life.

\section{Methods}

This was a retrospective cohort study that utilized an ongoing data base of all $\mathrm{CDH}$ cases treated at the University of lowa Hospital and Clinics. LHR was measured from antenatal ultrasounds and O/E LHR was calculated using the online database on TOTALtrial.com. OI data from previously published research study at the University of Iowa was used. The ANOVA test was used to analyze LHR data, while the Kruskal Wallis test was used to analyze O/E LHR and OI data. All analyses were performed using the SAS data analysis software.

\section{Results}

We identified 20 neonates with $\mathrm{CDH}$ and antenatal ultrasounds available for O/E LHR measurement. There were a total of 11 survivors and 9 nonsurvivors. The mean LHR was 1.62 $( \pm 0.84)$ for survivors and $0.87( \pm 0.54)$ for non-survivors $(P=0.034)$. The median O/E LHR was 29.9 (15-35.4) for survivors and 19 (16.7-23.4) for nonsurvivors, $P=0.425$. The median $\mathrm{Ol}$ was 12 (9-14) for survivors and 32 (25-41) for non-survivors, $P=0.016$. There were

\footnotetext{
${ }^{1}$ Department of Obstetrics and Gynecology, Carver College of Medicine, University of Iowa Hospitals and Clinics, lowa City, IA, 52242

${ }^{2}$ Department of Pediatrics, University of lowa Hospitals and Clinics, Iowa City, Iowa 52242

Please cite this abstract as: Okpala CU, Picconi J, Klein JM, Morris FH, Rijhsinghani A, Nuangchamnong N. Does observed vs expected lung head ratio correlate with neonatal survival in infants with congenital diaphragmatic hernias? Proc Obstet Gynecol. 2013;4(3):Article 13 [ 2 p.]. Available from: http://ir.uiowa.edu/pog/ . Free full text article.
}

Corresponding author: Christine U Okpala, Department of Obstetrics and Gynecology, University of lowa, 200 Hawkins Drive, lowa City, IA 42242, christine-okpala@uiowa.edu

Copyright: (c) 2014 Okpala, et al. This is an open-access article distributed under the terms of the Creative Commons Attribution License, which permits unrestricted use, distribution, and reproduction in any medium, provided the original author and source are credited. 
no survivors when the LHR was $<0.9$. There were no survivors when the OI was greater than 38 .

\section{Conclusions}

LHR and OI correlate with neonatal survival. O/E LHR does not correlate with neonatal survival.
Presented at "Practical Update in Ob/Gyn," the University of lowa Obstetrics and Gynecology Postgraduate conference, 24 October 2014, hotelVetro \& Conference Center, lowa City, lowa 52240. 